\title{
XXXIV. Report made to the class of physics and mathematics of the institute of france, upon a proposition made by M. Six, chief director of the fire-engines of paris, for substituting water saturated with sea salt instead of common water, for extinguishing fires
}

\section{Messr. Chaptal \& Messr. Monge}

To cite this article: Messr. Chaptal \& Messr. Monge (1807) XXXIV. Report made to the class of physics and mathematics of the institute of france, upon a proposition made by M. Six, chief director of the fire-engines of paris, for substituting water saturated with sea salt instead of common water, for extinguishing fires, Philosophical Magazine Series 1, 28:111, 253-256, DOI: 10.1080/14786440708563512

To link to this article: http://dx.doi.org/10.1080/14786440708563512

Published online: 18 May 2009.

Submit your article to this journal $\sqsubset$

山 Article views: 3 
XXXIV. Report made to the Class of Physics and Mathematics of the Institute of France, upon a Proposition made by M. Six, Chief Director of the Fire-Engines of Paris, for substituting Water saturated with Sea Salt instead of common Water, for extinguishing Fires. By Messrs. Chaptal and Monge*.

$T_{H E}$ advantages found by $M$. Six by employing the method he proposes are these:

1. To present a liquid which never freezes at the temperature of our climate.

2. To employ a liquid more proper than pure water for extinguishing fires.

3. To preserve for a longer time the casks, which are often broken from the water freezing in their insides.

4. To preserve the water from all decomposition.

5. To preserve the casks from the speedy destruction they suffer from"fresh water left in them in a state of rest.

In order to give a precise idea of the merit of the method suggested by M. Six, we think it right to examine the two following questions :

1. At what degree of cold does water freeze when saturated with different quantities of sea salt?

2. Does water saturated with sea salt attack and destroy the leathern pipes employed in fire-engines?

In order to answer the first question, we submitted to a cold of $-17^{\circ}$ of Reaumur, produced by the mixture of pounded ice and bruised sea salt, some phials filled with a solution of sea salt at various degrees of saturation, from two up to twenty degrees.

This experiment was several times repeated, and always upn six kilogrammes of ice, with about half that quantity of pounded sea salt, and at a temperature of about ten degrees.

We constantly obtained the following results :

1. The solutions at two, three, and eight degrees were frozen some minutes after their immersion in the mixture.

* Frone Billioth. Phys. Econ. for 1807 , tom, i. p. 274. 
The solutions above No. 12 were more tardy in freezing.

When the solution was at 16 degrees, the freezing did not take place sooner than $\mathbf{4 0}$ or $\mathbf{5 0}$ minutes.

In the solutions at 19 or 20 degrees, only some few icicles are formed around the edges of the mixture.

2. At a cold of twelve degrees, no solution freezes in a mass; all of them from 2 to 15 degrees are frozen upon the sides of the phial, and the layer of ice becomes more or less thick, always in an inverse ratio to the degree of saturation. The solutions at 19 and 20 degrees never froze at all.

3. When the mixture of salt and ice is formed, and the thermometer is down at $-17^{\circ}$, we may keep up this degree of cold for two hours at least, provided we slope the vessel so as to let the water flow out produced by the melting.

If we draw out the phials containing the solutions at the moment the thermometer begins to rise, we observe as follows :

1. The solutions which are below 10 degrees, present masses of ice only without any appearance of water, to such a degree of cold that these masses when carefully pounded do not, for some time, moisten the bodies upon which the operation takes place.

2. The solutions which mark from 10 to 1.6 degrees, present a soft kind of ice, which may be bent, and is of the consistence of sherbet.

3. The solutions which mark 18 and 20 degrees, present only some crystals of ice swimming in a limpid liquor, or fixed upon the sides of the vessels.

4. The thawing takes place more speedily in phials, when the liquor is at a high degree of saturation, and more slowly at the lower degrees, in such a manner that it follows vigorously and constantly the scale of saturation.

5. The icicles separated with care from the portion of water not frozen, and washed with pure water, present the following phænomena :

A. The water issuing from their melting is constantly salt.

B. The gravity of the water proceeding from the crystals of the solutions from 1 to 5 degrees, compared with that of 
the portion of the unfrozen solution, presented as follows :

In a flask containing 36 grammes of pure water, the water produced by the melting of the crystals No. 1 weighed 36 grammes 5 decigrammes; and the water not frozen, and cartfully sepn ted from the ice, weighed 36 grammes 6 decigrammes.

In the same flask, the water proceeding from the melting of the erystals No. 1 weighed 39 grammes 6 decigrammes; and the water not frozen weighed 39 grammes 8 decigrammes.

Although the results thus presented are not all necessary for answering the proposed question, we have thought it proper to report them all, in consequence of their appearing in opposition in some respects to the ideas hitherto entertained as to the free ing of salt water, and as they serve to clear up the processes followed in some northern districts for the extraction of salt from sea water, and perhaps tend to review and verify the theoretical principles of freezing.

The second question remaining to be examined, respects the injury that may be done to leather pipes by salt water.

In order to decide this question, they thought it best to be guided both by experiments and observation. They were informed by $M$. Bonjour, the director of the national salt works, that in the salt works of Meurthe they have for several centaries ased, for raising the salt water, pumps in the cylinders of which round pieces of leather have been fixed; and that notwithstanding the uninterrupted usage of these pumps, and the contact of water saturated at 16 degrees, no alteration nor deterioration had taken place which could be attributed to the action of this liquid.

But even if it were true, that the saturated solution of salt attacked the leather or rendered it brittle, yet we do not think salt water should be rejected on that account, because M. Six with justice observes, that in the present state of the service they carefully wash the fire pumps and their pipes as soon as they have been used, in order to clear them from 
any impurities that may be deposited by the muddy waters of rivers, or the putrid water from casks.

Salt water, therefore, will not require any new precautions on the part of the firemen, and the leather of the pipes will not be moistened with it long enough to injure them. The reporters therefore are of opinion that the suggestions of M. Six present real advantages, and deserve to te adopted.

XXXV. Report of Surgical Cases in the City Dispensary, Grocers-Hall-Court, Poultry, from the Beginning of March to the End of June 1807: with Remarks on the Propriety of establishing a Fund for the Relief of the Ruptured Poor. By John Taunton, Esq.

$\mathbf{I}_{\mathrm{N}}$

$\mathrm{N}$ the last surgical report (see Philosophical Magazine, vol. xxvii. no. cvii. p. 236.) there were 144 patients under cure, from which period, during the four succeeding months, ending in June, there were admitted 473 persons.

\begin{tabular}{lrrr} 
Cured & - & - & 392 \\
Relieved & - & - & 11 \\
Died & & - & 2 \\
Under cure & - & 212 \\
\hline 617
\end{tabular}

Having noticed the frequent occurrence and danger of hernia (vol. xxvii. p. 236), which do not appear to have been sufficiently appreciated, or funds would have been raised in different districts for the purpose of affording relief to those who have it not in their power to relieve themselves; whether the want of ability arise from pure indigence, or from indiscretion, it nust be admitted that the afflicted are entitled to the charitable consideration of a humane public.

In this metropolis (which is truly characterized as being pre-eminent to all cities in the world on account of its charitable institutions) it certainly appears that this disease has not passed unnoticed, as a "Society for the Relief of the Ruptured 